\title{
Validity of an FFQ assessing the vitamin D intake of young Serbian women living in a region without food fortification: the method of triads model
}

\author{
Marija Diekic-lvankovic ${ }^{1,2}$, Hope A Weiler ${ }^{2}$, Marina Nikolic ${ }^{1}$, Agnes Kadvan ${ }^{1}$, \\ Mirjana Gurinovic ${ }^{1}$, Ljuba M Mandic ${ }^{3}$ and Maria Glibetic ${ }^{1, *}$ \\ ${ }^{1}$ Centre of Research Excellence in Nutrition and Metabolism, Institute for Medical Research, University of Belgrade, \\ Tadeusa Koscuska 1, 11000 Belgrade, Serbia: ${ }^{2}$ School of Dietetics and Human Nutrition, McGill University, \\ Macdonald Campus, Ste. Anne-de-Bellevue, Québec, Canada: ${ }^{3}$ Faculty of Chemistry, University of Belgrade, \\ Belgrade, Serbia
}

Submitted 27 October 2014: Final revision received 16 March 2015: Accepted 26 March 2015: First published online 11 May 2015

\begin{abstract}
Objective: The objective of the present study was to examine the external validity of an FFQ designed to estimate dietary vitamin D intake compared with a plasma biomarker and three repeated $24 \mathrm{~h}$ dietary recalls in women of reproductive age in Serbia, where there is no exposure to food fortified with vitamin D. The method of triads was applied.

Design: In a cross-sectional study, 422 women completed the Women and Reproductive Health FFQ (WRH-FFQ) during the winter months. From a representative subgroup $(n 44)$, three $24 \mathrm{~h}$ dietary recalls and anthropometric parameters were collected as well as a fasting blood sample for vitamin D biomarker analyses. Correlation coefficients were calculated between each of the dietary methods. Validity coefficients, as a correlation between the measured and estimated 'true' exposure, were calculated using the method of triads. Bland-Altman plots were also constructed.

Setting: Three major universities in Serbia.

Subjects: Healthy young women ( $n$ 422) aged $18-35$ years.

Results: The WRH-FFQ estimate of vitamin D intake for all participants was 4.0 (sD 3.3) $\mu \mathrm{g} / \mathrm{d}$ and 3.1 (SD 2.3) $\mu \mathrm{g} / \mathrm{d}$ for the subgroup. Bland-Altman plots for these intakes showed high agreement. Validity coefficients for the FFQ, $24 \mathrm{~h}$ recall and biomarker were $\rho_{\mathrm{QI}}=0.847$ (95\% CI 0.564, 0.928), $\rho_{\mathrm{RI}}=0.810$ (95\% CI 0.537 , $0.997)$ and $\rho_{\mathrm{BI}}=0.499(95 \%$ CI $0.190,0.840)$, while the correlation coefficients were $0.686,0.422$ and 0.404 .

Conclusions: The FFQ applied in the present study is a valid tool for assessing dietary vitamin $\mathrm{D}$ intake in women living in Serbia, a region without mandatory vitamin $\mathrm{D}$ food fortification.
\end{abstract}

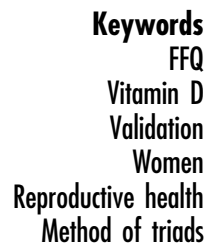

Maintenance of optimal nutritional status in women of reproductive age can help to ensure normal fetal development $^{(1)}$. It has been shown that vitamin $\mathrm{D}$ has important benefits during fetal and neonatal development ${ }^{(2)}$. Vitamin D, a fat-soluble vitamin, can be attained through diet, supplements or exposure to sunlight. The primary function of vitamin $\mathrm{D}$ is to control Ca homeostasis and in doing so aid absorption of $\mathrm{Ca}$ from the intestine and ensure adequate bone metabolism ${ }^{(2)}$. Vitamin D status before and during pregnancy is implicated in fetal growth ${ }^{(3)}$. In addition, vitamin $\mathrm{D}$ is important for the prevention of adverse pregnancy outcomes including pre-eclampsia and gestational diabetes mellitus ${ }^{(4-6)}$.
The RDA for vitamin $\mathrm{D}$ set by the US Institute of Medicine (IOM) is $15 \mu \mathrm{g} / \mathrm{d}$ for ages $1-70$ years with no additional amount during pregnancy or lactation ${ }^{(7)}$. As many as $41 \%$ of all pregnancies worldwide are unplanned ${ }^{(8)}$. To ensure that the general population and women of childbearing age consume enough vitamin $\mathrm{D}$ prior to becoming pregnant, many countries have introduced mandatory vitamin D fortification of food, which is not the case in Serbia. To date voluntary fortification in Serbia is limited to one milk product and imported products.

Mapping low intakes of vitamin D and other micronutrients across Europe with a focus on Central Eastern European (CEE) countries showed no differences in 
micronutrient intake/status compared with other European regions and highlighted the lack of comparable studies on micronutrient intake/status across all age ranges in the CEE region ${ }^{(9)}$. Available evidence for Serbia indicated that intake of vitamin D is below $15 \mu \mathrm{g} / \mathrm{d}$ suggested by the authorities ${ }^{(10)}$.

In order to identify possible vitamin $\mathrm{D}$ nutritional inadequacies in women of reproductive age in CEE countries, there is a need for standardized dietary assessment tools. To address this concern we developed an FFQ and undertook the present study to determine whether the FFQ is valid for assessing the dietary intake of vitamin D in women of reproductive age in a Balkan region. This validation study was conducted at the end of winter, when subcutaneous production of vitamin D is negligible because UVB exposure is minimal and therefore it would make a minor contribution to vitamin D status.

\section{Materials and methods}

FFQ are a widely used dietary assessment tool for estimating the usual dietary intake ${ }^{(11)}$. In terms of validation of an FFQ, it has been suggested that two reference methods should be used, such as repeated $24 \mathrm{~h}$ dietary recalls, weighed food records, food diaries or biomarkers ${ }^{(11-13)}$. Biomarkers as a reference method have the advantage of having errors uncorrelated with those that may be shared by methods relying on self-report ${ }^{(14)}$. Therefore, in the present study, the FFQ was validated against $24 \mathrm{~h}$ recalls and a biomarker, plasma 25-hydroxyvitamin D (25(OH)D), using the lower bound of the true questionnaire validity approach ${ }^{(13)}$. We used the method of triads, a triangular approach to validation that uses the correlations between each of the three methods to calculate a validity coefficient. The validity coefficient is the correlation between the dietary intake reported by the FFQ and the unknown 'true' dietary intake ${ }^{(15)}$.

\section{Participants}

As a part of national integrated project, a cross-sectional study was conducted between November 2010 and April 2011 in order to investigate dietary intake and status of vitamin D in Serbian women of reproductive age.

Females, aged 18 to 35 years, were recruited using flyers and verbal referral from three universities in Serbia that spread across three provinces (University of Belgrade, University of Novi Sad and University of Nis) to represent $0 \cdot 1 \%$ of the total number of women aged $18-35$ years in Serbia ${ }^{(16)}$. Inclusion criteria comprised healthy women without chronic diseases. Professional athletes, pregnant or breast-feeding women were excluded from the study.

A total of 500 women were recruited on a voluntary basis to participate in the study with 422 females completing the FFQ on one occasion, a response rate $84.4 \%$.

A subgroup of randomly selected participants ( $n$ 50) was studied for additional measures in March 2011 which included three repeated $24 \mathrm{~h}$ recalls, anthropometric measurements and a blood sample. The response rate for the anthropometry and $24 \mathrm{~h}$ recalls was $88.0 \%(n 44)$ and for blood sampling was $46.0 \%$ ( $n$ 23). However, three women were excluded due to UVB exposure.

\section{Anthropometry}

Anthropometry was performed without shoes and jacket, including height to the nearest $0.1 \mathrm{~cm}$ (Perspective Enterprises, Kalamazoo, MI, USA) and weight to the nearest $0.5 \mathrm{~kg}$ using a body composition analyser (TBF-300; Tanita Corp., Tokyo, Japan).

\section{$\boldsymbol{F F Q}$}

The Women and Reproductive Health FFQ (WRH-FFQ) was developed by combining the NCI/Block Health Habits and History Questionnaire ${ }^{(17)}$ with a validated FFQ for folate in the Balkan region ${ }^{(18)}$. The combined FFQ was further adapted by inclusion of a wider section of foods containing vitamin D as well as traditional foods consumed in Serbia. A translation was conducted from English to Serbian by three bilingual experts in nutrition and dietetics and back-translated to ensure content validity.

The WRH-FFQ reflected the previous $30 \mathrm{~d}$ and was self-administered in the presence of trained dietitians. Instructions related to frequencies of consumption and portion sizes (small, medium, large) were presented on photographs included in the WRH-FFQ. For the food items, the frequency intervals were 'never', 'once per month', '2-3 times per month', 'once a week', '2-3 times per week', '4-6 times per week' and 'every day'. All reported frequencies were converted to frequencies per day. The questionnaire contained ninety food items and twelve additional questions regarding the frequency of use of multivitamin/mineral and other supplements as well as voluntary and imported vitamin D-fortified products available in Serbia. Foods consumed sometimes, but not captured in the food list, were recorded at the end of the FFQ. The WRH-FFQ also contained a general questionnaire on age, education level, previous medical conditions, detailed vitamin supplements and medication use, lifestyle habits (smoking, physical activity/exercise, alcohol and coffee/tee consumption), as well as tanning from a solarium or natural sunlight (on vacation) during the last 3 months.

\section{Twenty-four bour dietary recall}

Three $24 \mathrm{~h}$ dietary recalls were performed by multiple pass in March 2011. The first one was conducted by trained professionals in our clinic on the day of blood sampling, during the last week of the month covered by the FFQ. The second and third recalls were conducted after the FFQ by telephone within 2 weeks ${ }^{(19)}$, with two of the recalls being on weekdays and one on a weekend day. Women reported the dietary intake for each day from 
breakfast until the next morning. Pictures of household measures were used for specific information on portion sizes.

\section{Calculation of nutrient intakes}

Nutrient intakes resulting from the FFQ and $24 \mathrm{~h}$ recalls were estimated using the Serbian Food Composition Database $^{(20)}$. Manufacturer specifications were used to estimate the nutrient content of supplements. The total daily intake of vitamin $\mathrm{D}(\mu \mathrm{g} / \mathrm{d})$ was calculated using the dietary assessment software tool DIET ASSESS used in national and regional consumption studies and evaluated in a European Food Safety Authority (EFSA) project ${ }^{(21)}$. Energy-adjusted dietary vitamin D intake was calculated using the nutrient density method proposed by Willett ${ }^{(22)}$. Intake of vitamin D from supplements is not related to energy intake and thus the raw value of vitamin D intake from supplements was added to the crude or energyadjusted dietary vitamin $\mathrm{D}$ intake to obtain a single value for total vitamin $\mathrm{D}$ intake ${ }^{(23)}$. Finally, the total vitamin $\mathrm{D}$ intake of participants was related to both the RDA $(15 \mu \mathrm{g} / \mathrm{d})$ and the Estimated Average Requirement (EAR; $10 \mu \mathrm{g} / \mathrm{d}$ ) for vitamin D for adults (19-50 years) according to the IOM recommendations ${ }^{(24)}$. The proportions of women above and below the RDA and the EAR were calculated since these recommendations are set based on dietary intake data $^{(25)}$ and are meant to represent healthy levels of intake in accordance with good vitamin D status in the absence of UVB exposure ${ }^{(26)}$.

\section{Vitamin D status assessment}

A single measurement of $25(\mathrm{OH}) \mathrm{D}$, with a known half-life to up to 1 month, was selected to reflect vitamin D status consistent with the time period reflected in the $\mathrm{FFQ}^{(27)}$. After an overnight fast, venous blood samples were collected from twenty-three randomly selected participants into lithium heparin tubes by clinical staff at the Centre of Research Excellence in Nutrition and Metabolism, University of Belgrade, March 2011. Blood was immediately processed and plasma frozen at $-80^{\circ} \mathrm{C}$. Plasma samples were shipped to Canada (McGill University) on dry ice and stored at $-80^{\circ} \mathrm{C}$ until analysis. Vitamin D concentration was measured using the LIAISON total 25(OH)D assay (DiaSorin Inc., Stillwater, MN, USA). The intra-assay CV of $3 \cdot 18 \%$ (range $0 \cdot 55-7 \cdot 17 \%$ ) was calculated from repeated measurement of a pooled plasma sample used as a laboratory reference range for healthy adults and from DiaSorin high and low controls. The accuracy using the mid-range of manufacturer specifications was $104 \%$ for DiaSorin low control and $103 \%$ for DiaSorin high control; and $97.00 \%$ for NIST SRM 972a level 1 and 90.44\% for NIST SRM 972a level 2 (Standard Reference Material from the National Institute of Standards and Technology, Gaithersburg, MD, USA). This laboratory participates in the DEQAS (Vitamin D External Quality
Assessment Scheme) programme and obtained a Certificate of Proficiency for 2013-2014, which reflects that $75 \%$ or more of the reported results fell within $25 \%$ of the ALTM (all-laboratory trimmed mean).

\section{Ethical approval}

The study was conducted according to the guidelines laid down in the Declaration of Helsinki and all procedures were approved by the Ethics Review Board in Serbia and the McGill Institutional Review Board of the Faculty of Agricultural and Environmental Science for analyses in Canada. Written informed consent was obtained from all participants.

\section{Statistical analysis}

Several methods were used to assess the validity of the WRH-FFQ. Data were not normally distributed and crude as well as energy-adjusted Spearman rank-correlation coefficients were calculated between daily vitamin D intake and the biomarker of vitamin D status. Bland-Altman plots were used to compare the FFQ and $24 \mathrm{~h}$ recall for quantifying vitamin D intake. As variability of the difference between measurements was not uniform along the range of the measurement values, the Bland-Altman analysis was performed on the log scale (log-transformed difference) ${ }^{(28)}$. The ability of the WRH-FFQ to correctly classify participants into quartiles of the referent method (24h recall) and biomarker was also determined. Percentages of those correctly classified (participants classified within the same quartiles), closely classified (participants classified within the same or adjacent quartiles) and grossly misclassified (participants classified in the opposite quartiles) were calculated. The triangular approach to validation, known as the method of triads, was applied as well. The following equation was used to calculate the validity coefficient (VC) for the FFQ:

$$
\rho_{\mathrm{QI}}=\sqrt{r_{\mathrm{QB}} \times \frac{r_{\mathrm{QR}}}{r_{\mathrm{BR}}}}
$$

where $\rho_{\mathrm{QI}}$ represents the validity coefficient for the FFQ, $r_{\mathrm{QB}}$ the correlation between the FFQ and the biomarker, $r_{\mathrm{BR}}$ the correlation between the $24 \mathrm{~h}$ recall and the biomarker, and $r_{\mathrm{QR}}$ the correlation between the FFQ and the $24 \mathrm{~h}$ recall. This method has been described in detail by Ocke and Kaaks ${ }^{(29)}$. Calculated validity coefficient was used as the upper limit of the validity coefficient, whereas the correlation between the biomarker and the FFQ was interpreted as the lower limit of the validity coefficient. The $95 \%$ confidence intervals for the validity coefficients were estimated using bootstrap sampling where 1000 samples of equal size ( $n$ 20) were obtained with replacement from the study subjects ${ }^{(29,30)}$.

Participants' vitamin D status was classified as deficiency or into categories generally considered inadequate or adequate for bone and overall health in healthy individuals, 
based on $25(\mathrm{OH}) \mathrm{D}$ level ${ }^{(24)}$. The report from the IOM in 2011 proposed definitions for deficient $(25(\mathrm{OH}) \mathrm{D}$ level $<30 \mathrm{nmol} / \mathrm{l})$, inadequate $(25(\mathrm{OH}) \mathrm{D}$ level between 30 and $50 \mathrm{nmol} / \mathrm{l})$, sufficient $(25(\mathrm{OH}) \mathrm{D}$ level between 50 and 125 $\mathrm{nmol} / \mathrm{l})$ and potentially toxic (25(OH)D level $>125 \mathrm{nmol} / \mathrm{l})$ levels of $25(\mathrm{OH}) \mathrm{D}^{(7,31,32)}$.

Statistical analysis was performed using the software MedCalc version $10 \cdot 2 \cdot 0 \cdot 0$ and the statistical software package IBM SPSS Statistics 20.0. A $P$ value $<0.05$ was considered statistically significant.

\section{Results}

The WRH-FFQ was completed by 422 participants. A subgroup of forty-four women completed both the FFQ and three $24 \mathrm{~h}$ dietary recalls, while twenty-three of them were enrolled in the validation study with assessed vitamin D status. Mean age (23.3 (SD 2.4) years $v .25 .5$ (SD 2.2) years $v$. $25 \cdot 6$ (SD 2.4) years), height (166.2 (sD 26.2) $\mathrm{cm} v .170 \cdot 6$ (SD 5.5) cm $v .171 \cdot 6(\mathrm{sD} 5 \cdot 2) \mathrm{cm}$ ), weight $(58 \cdot 3$ (SD 12.8) $\mathrm{kg} v$. 61.5 (sD 6.4) $\mathrm{kg} v .61 .9(\mathrm{sD} 5.7) \mathrm{kg}$ ) and BMI (20.7 (SD 2.2) $\mathrm{kg} / \mathrm{m}^{2} v \cdot 21 \cdot 2(\mathrm{sD} 2 \cdot 2) \mathrm{kg} / \mathrm{m}^{2}$ v. $21 \cdot 0(\mathrm{sD} 2 \cdot 1) \mathrm{kg} / \mathrm{m}^{2}$ ) did not differ between the main sample, the subgroup and the validation group, respectively. Self-reported BMI in the FFQ (21.5 (sD $2 \cdot 1) \mathrm{kg} / \mathrm{m}^{2}$ ) was very similar to measured BMI $\left(21.2(\mathrm{sD} 2 \cdot 2) \mathrm{kg} / \mathrm{m}^{2}\right)$ in the subgroup. All participants were highly educated or enrolled in a university when the study was conducted, $15.0 \%$ were smokers and $68.3 \%$ consumed alcohol on a weekly basis, $47.3 \%$ consumed 2-3 cups coffee/d and $47 \cdot 7 \%$ consumed $4-5$ cups/d. No physical activity was reported by $30 \%$ of all participants, while up to $70 \%$ stated some physical activity. In the subgroup, $22.7 \%$ were not active while $77.3 \%$ were physically active typically between $30 \mathrm{~min}$ and $3.5 \mathrm{~h}$ weekly.

Plasma 25(OH)D was 29.5 (sD 13.8) nmol/l (n 20). Ninety per cent had 25(OH)D level below $50 \mathrm{nmol} / \mathrm{l}$, while $70 \%$ had $25(\mathrm{OH}) \mathrm{D}$ level below $30 \mathrm{nmol} / \mathrm{l}$. Vitamin D intake was below the EAR for $96 \%$ of all participants as assessed by the WRH-FFQ ( $n$ 422). None of the 422 participants in the main sample consumed vitamin D-fortified food and only $4.7 \%$ used vitamin D in multivitamin supplements. No participants of the subgroup reported vitamin supplement use.

Regardless of methodology, all women were below the RDA. Estimated daily energy and nutrient intakes assessed by the WRH-FFQ and the average of the three $24 \mathrm{~h}$ dietary recalls are presented in Table 1 . The top six food sources

Table 1 Daily energy and nutrient intakes assessed by the WRH-FFQ and average of the three $24 \mathrm{~h}$ dietary recalls among Serbian women of reproductive age, November 2010-April 2011

\begin{tabular}{|c|c|c|c|c|c|c|c|c|c|c|}
\hline & \multirow{2}{*}{\multicolumn{2}{|c|}{$\begin{array}{l}\text { Main sample } \\
\text { FFQ (n 422) }\end{array}$}} & \multicolumn{4}{|c|}{ Subgroup } & \multicolumn{4}{|c|}{ Validation group } \\
\hline & & & \multicolumn{2}{|c|}{ FFQ $(n 44)$} & \multicolumn{2}{|c|}{$24 \mathrm{~h}$ recalls $(n 44)$} & \multicolumn{2}{|c|}{ FFQ $(n$ 23) } & \multicolumn{2}{|c|}{$24 \mathrm{~h}$ recalls $(n 23)$} \\
\hline & Mean & SD & Mean & SD & Mean & SD & Mean & SD & Mean & SD \\
\hline Energy $(\mathrm{kJ})$ & 6988.5 & $2940 \cdot 1$ & $6442 \cdot 1$ & 1789.5 & $5978 \cdot 1$ & 1208.5 & $6577 \cdot 2$ & $1910 \cdot 4$ & $6075 \cdot 6$ & $1300 \cdot 0$ \\
\hline Total carbohydrates (\%TEI) & $51 \cdot 2$ & 13.0 & $54 \cdot 1$ & $15 \cdot 3$ & $42 \cdot 3$ & 7.5 & $52 \cdot 8$ & 14.2 & $42 \cdot 1$ & 9.6 \\
\hline Total fat $(\%$ TEI) & $28 \cdot 1$ & $6 \cdot 8$ & $27 \cdot 3$ & $6 \cdot 8$ & $32 \cdot 1$ & 4.9 & 26.5 & 5.9 & $31 \cdot 8$ & $5 \cdot 6$ \\
\hline Protein (\%TEI) & $24 \cdot 1$ & $5 \cdot 7$ & $22 \cdot 6$ & $6 \cdot 3$ & $18 \cdot 4$ & $2 \cdot 9$ & 21.3 & 5.9 & $19 \cdot 4$ & $3 \cdot 0$ \\
\hline Vitamin D $(\mu \mathrm{g})^{\star}$ & 4.0 & $3 \cdot 3$ & $3 \cdot 1$ & $2 \cdot 3$ & $2 \cdot 2$ & $2 \cdot 0$ & $2 \cdot 7$ & $1 \cdot 7$ & $1 \cdot 8$ & 1.6 \\
\hline Vitamin D $(\mu \mathrm{g} / 4184 \mathrm{~kJ})^{*}$ & $2 \cdot 4$ & 1.6 & $2 \cdot 0$ & 1.6 & 1.5 & 1.3 & 1.7 & $1 \cdot 2$ & 1.2 & 1.0 \\
\hline $\mathrm{Ca}(\mathrm{mg})$ & $682 \cdot 7$ & $6 \cdot 2$ & $645 \cdot 4$ & 224.5 & $538 \cdot 4$ & $260 \cdot 8$ & $634 \cdot 7$ & 232.5 & $628 \cdot 8$ & $297 \cdot 3$ \\
\hline
\end{tabular}

WRH-FFQ, Women and Reproductive Health FFQ; \%TEI, percentage of total energy intake.

${ }^{*} 1 \mu \mathrm{g}$ vitamin $\mathrm{D}=40 \mathrm{IU}$ vitamin $\mathrm{D} ; 4184 \mathrm{~kJ}=1000 \mathrm{kcal}$.

Table 2 Top six food sources of vitamin D assessed by the WRH-FFQ and $24 \mathrm{~h}$ dietary recalls among Serbian women of reproductive age, November 2010-April 2011

\begin{tabular}{|c|c|c|c|c|c|c|c|}
\hline \multirow[b]{3}{*}{ Food } & \multicolumn{4}{|c|}{$\mathrm{FFQ}$} & \multirow[b]{3}{*}{ Food } & \multirow{2}{*}{\multicolumn{2}{|c|}{$\frac{24 \mathrm{~h} \text { recalls }}{\text { Subgroup }(n 44)}$}} \\
\hline & \multicolumn{2}{|c|}{ Main sample (n 422) } & \multicolumn{2}{|c|}{ Subgroup ( $n$ 44) } & & & \\
\hline & $\begin{array}{c}\text { No. of } \\
\text { consumers }\end{array}$ & $\begin{array}{c}\% \text { of } \\
\text { consumers }\end{array}$ & $\begin{array}{c}\text { No. of } \\
\text { consumers }\end{array}$ & $\begin{array}{c}\% \text { of } \\
\text { consumers }\end{array}$ & & $\begin{array}{c}\text { No. of } \\
\text { consumers }\end{array}$ & $\begin{array}{c}\% \text { of } \\
\text { consumers }\end{array}$ \\
\hline Freshwater fish & 301 & 71 & 32 & 73 & Trout (freshwater fish) & 15 & 34 \\
\hline Salmon & 175 & 41 & 14 & 32 & Salmon & 8 & 18 \\
\hline Tuna & 329 & 78 & 36 & 82 & Tuna & 18 & 41 \\
\hline Sardine & 221 & 52 & 19 & 43 & Sardine & 14 & 32 \\
\hline Meat & 408 & 97 & 43 & 98 & Meat & 43 & 98 \\
\hline Eggs & 357 & 85 & 36 & 82 & Eggs & 35 & 80 \\
\hline
\end{tabular}

WRH-FFQ, Women and Reproductive Health FFQ.

Freshwater fish includes trout, catfish and carp; meat includes pork, beef, lamb, veal, chicken, turkey, liver, weiners, cold cuts, dried sausage and other dried meats. 
(a)
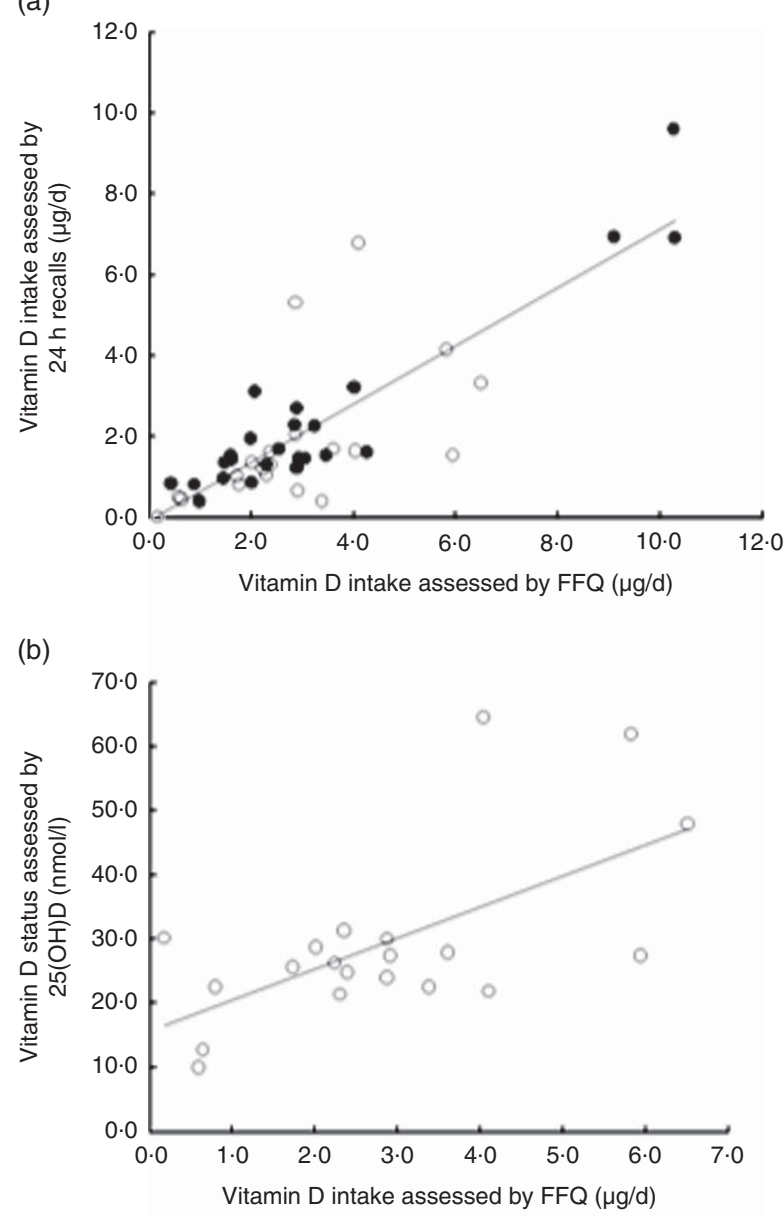

(c)

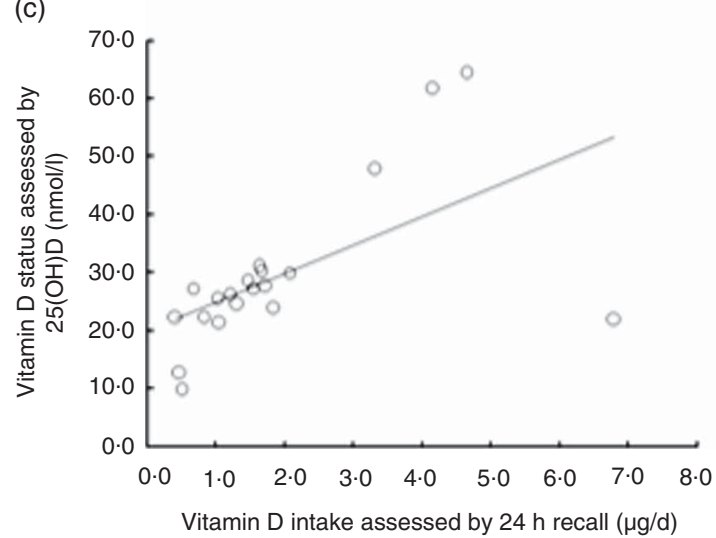

Fig. 1 Correlations between crude vitamin $D$ intake assessed by (a) the WRH-FFQ and the average of three $24 \mathrm{~h}$ dietary recalls, (b) the FFQ and the biomarker of vitamin D status (plasma 25-hydroxyvitamin $\mathrm{D}(25(\mathrm{OH}) \mathrm{D})$ ) and (c) the $24 \mathrm{~h}$ recalls and the biomarker of vitamin $D$ status among Serbian women of reproductive age, November 2010-April 2011: •, participants without 25(OH)D status determined ( $n$ 44); $\circ$, participants with $25(\mathrm{OH}) \mathrm{D}$ status determined $(n 20)$. All correlations were significant: (a) $r=0.701, P<0.0001$; (b) $r=0.422, P<0.05$; (c) $r=0.404$, $P<0.05$ (WRH-FFQ, Women and Reproductive Health FFQ)

of vitamin D in Serbia identified by the WRH-FFQ and $24 \mathrm{~h}$ recalls were fatty fish (Table 2 ), with all varieties being imported with the exception of trout (freshwater fish). (a)

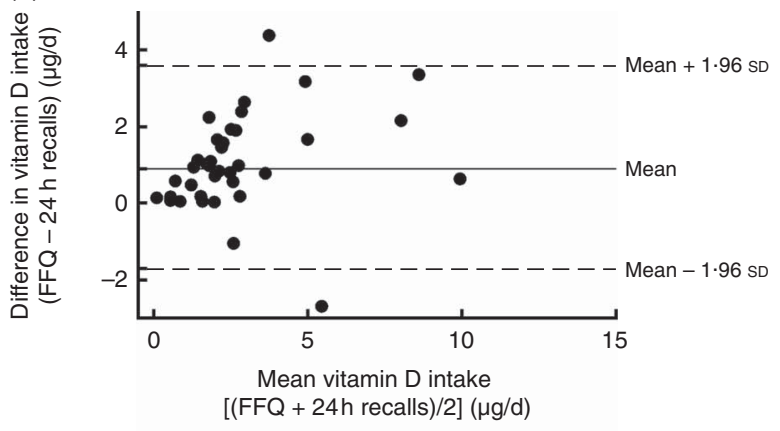

(b)

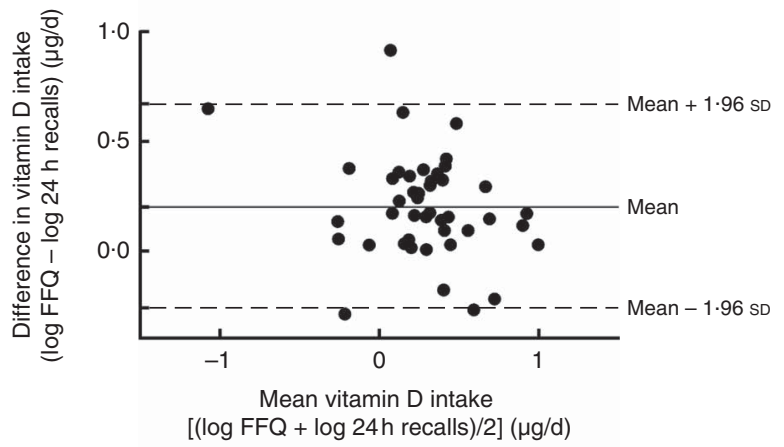

(c)

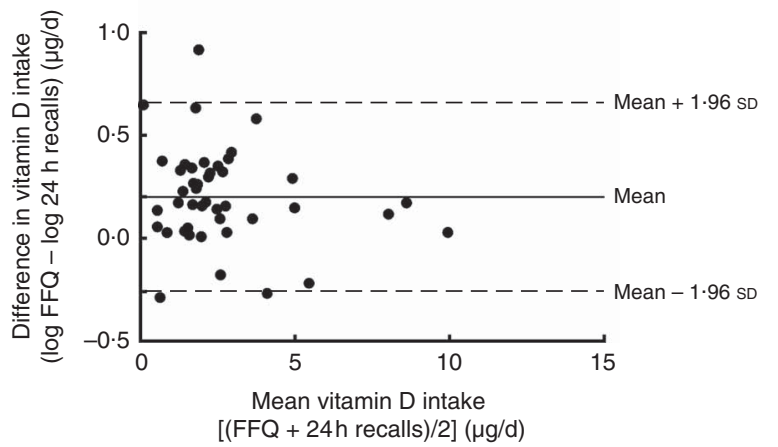

Fig. 2 Bland-Altman plots assessing the agreement between the $\mathrm{WRH}-\mathrm{FFQ}$ and the average of three $24 \mathrm{~h}$ dietary recalls for estimating vitamin $D$ intake among a subgroup of participants ( $n$ 44); Serbian women of reproductive age, November 2010April 2011. For each participant: (a) the difference in vitamin D intakes between the two methods was plotted against the mean vitamin $D$ intake by the two methods; (b) the difference in log vitamin D intakes between the two methods was plotted against the mean log vitamin $\mathrm{D}$ intake by the two methods; and (c) the difference in log vitamin D intakes between the two methods was plotted against the mean vitamin $D$ intake by the two methods. - mean difference; - - -, $95 \%$ limits of agreement (WRH-FFQ, Women and Reproductive Health FFQ)

Correlations between the WRH-FFQ, $24 \mathrm{~h}$ recalls and biomarker of vitamin D status are presented in Fig. 1. The crude and energy-adjusted Spearman rank-correlation coefficients between total vitamin $\mathrm{D}$ intakes assessed by the FFQ, $24 \mathrm{~h}$ recalls and biomarker of vitamin D status have similar patterns. Although the energy-adjusted Spearman rank-correlation coefficient between total vitamin D intake assessed by the FFQ and the vitamin D 
Table 3 Cross-classification (\%) of vitamin D intake into quartiles by the WRH-FFQ and validation methods (average of three $24 \mathrm{~h}$ recalls and biomarker, i.e. plasma 25 -hydroxyvitamin $\mathrm{D}(25(\mathrm{OH}) \mathrm{D})$ ) for twenty participants, Serbian women of reproductive age, November 2010-April 2011

\begin{tabular}{lccc}
\hline & \multicolumn{3}{c}{ Vitamin D intake assessed by FFQ } \\
\cline { 2 - 4 } $\begin{array}{l}\text { Vitamin D intake } \\
\text { assessed by }\end{array}$ & $\begin{array}{c}\text { Same } \\
\text { quartile }\end{array}$ & $\begin{array}{c}\text { Same or adjacent } \\
\text { quartile }\end{array}$ & $\begin{array}{c}\text { Opposite } \\
\text { quartile }\end{array}$ \\
\hline 24 h recalls & 65 & 80 & 20 \\
25(OH)D & 50 & 80 & 20 \\
\hline
\end{tabular}

WRH-FFQ, Women and Reproductive Health FFQ.

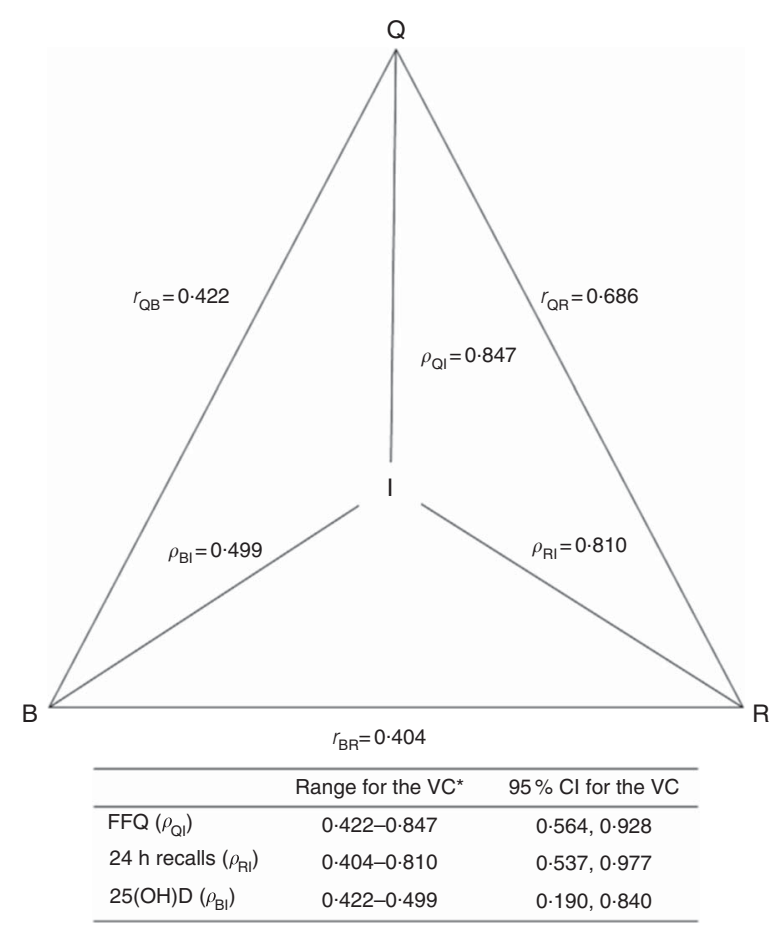

Fig. 3 Triangular relationship of the correlation coefficients $\left(r_{\mathrm{QB}}, r_{\mathrm{RB}}, r_{\mathrm{QR}}\right)$ between vitamin $\mathrm{D}$ intake estimated by the $\mathrm{WRH}$ FFQ $(Q)$, the average of three $24 \mathrm{~h}$ dietary recalls $(R)$ and the biomarker $(B)$ of vitamin $D$ status (plasma 25-hydroxyvitamin $D$ $(25(\mathrm{OH}) \mathrm{D}))$ and validity coefficients (VC: $\left.\rho_{\mathrm{Ql}}, \rho_{\mathrm{Bl}}, \rho_{\mathrm{RI}}\right)$ between true intake (I) and estimated intakes, with $95 \%$ confidence intervals. ${ }^{*}$ The lower limit is $r_{\mathrm{QB}}$ for the FFQ and the biomarker and $r_{\mathrm{BR}}$ for the $24 \mathrm{~h}$ recalls, and the upper limit is calculated by the method of triads (WRH-FFQ, Women and Reproductive Health FFQ)

biomarker was $0.415 \quad(P=0.001$, data not shown), the relationship was similar using the crude data $(r=0.422, \quad P=0.032)$. The Spearman rank-correlation coefficient between energy-adjusted vitamin D intake assessed by the $24 \mathrm{~h}$ recalls and biomarker was not statistically significant $(r=0.346, \quad P=0.067$; data not shown), whereas it was significant using the crude data $(r=0.404, P=0.039)$.

The Bland-Altman plots showed high agreement between vitamin $\mathrm{D}$ intakes calculated by the WRH-FFQ and $24 \mathrm{~h}$ dietary recalls (Fig. 2).
Nutrient intakes were divided into quartiles in order to evaluate the ability of the WRH-FFQ to rank women into the same quartiles as the $24 \mathrm{~h}$ dietary recalls and $25(\mathrm{OH}) \mathrm{D}$ concentration (Table 3). Classification into quartiles showed that, on average, $80 \%$ of the women were classified into the same or adjacent quartile when ranked by the FFQ and $24 \mathrm{~h}$ recalls as well as according to their vitamin D status (biomarker) and less than 20\% were misclassified into opposite quartiles by both methods (Table 3).

The correlations between each of the three methods were used to calculate the validity coefficients (VC: $\rho_{\mathrm{QI}}$, $\left.\rho_{\mathrm{BI}}, \rho_{\mathrm{RI}}\right)$ for the WRH-FFQ using the method of triads approach. The validity coefficients for the FFQ and $24 \mathrm{~h}$ dietary recalls were higher than those for the serum biomarker (Fig. 3). However, the validity coefficients for the FFQ tended to be higher than those for both the $24 \mathrm{~h}$ recalls and the biomarker.

\section{Discussion}

The aim of the present study was to validate the WRH-FFQ for the assessment of vitamin D intake in young women of reproductive age in a country without mandatory vitamin $\mathrm{D}$ food fortification. Therefore, we collected dietary intake data by two dietary assessment methods (FFQ and three $24 \mathrm{~h}$ dietary recalls), determined concentrations of a nutritional biomarker (plasma 25(OH)D) and applied the method of triads for validation analyses.

In the present study, validity coefficients were high between the 'true' intake (I) and the FFQ (0.847) as well as the $24 \mathrm{~h}$ recalls $(0 \cdot 810)$ and moderate for the biomarker (0.499). Our results for validity coefficients are similar to those in studies that used the method of triads model for validation of FFQ for different nutrients such as erythrocyte folate $(0.750)$, vitamin $\mathrm{B}_{12}(0.850)$, $\alpha$-carotene $(0.850)$ and total carotenoids $(0.550)^{(33-35)}$. The $95 \%$ confidence intervals for the validity coefficients in our study are narrow and the upper limit for the intervals is lower than 1 . This is a strength which reflects an absence of random sampling variations between dietary methods or violations in the underlying assumptions of the model $^{(29,36)}$.

In our study of 422 healthy young women who completed the WRH-FFQ, the estimated vitamin D intake was $4 \mu \mathrm{g} / \mathrm{d}$. This is comparable with published data from Serbia for adult women $(5 \mu \mathrm{g} / \mathrm{d} \text { assessed by } 7 \mathrm{~d} \text { food record })^{(37)}$, but the age range for women was wider in that study and the relative difference could be explained by nutrient intake calculations using an older version of food composition data that relied on calculated vitamin D content rather than analytical assessment. Our vitamin D intake assessed by WRH-FFQ and $24 \mathrm{~h}$ recall is similar to findings from other studies in the region that assessed vitamin D intake by an alternative FFQ (Portugal: $4 \mu \mathrm{g} / \mathrm{d}$ ) ${ }^{(38)}$ as well as by $24 \mathrm{~h}$ recall using calculated values (Poland: $4 \mu \mathrm{g} / \mathrm{d}$; 
Hungary: $2 \mu \mathrm{g} / \mathrm{d})^{(9,39)}$. Vitamin D-containing supplements were used by less than $5 \%$ of all 422 participants and no one reported consumption of the voluntarily vitamin D-fortified food product on the market (i.e. long-lasting pasteurised milk with added vitamin A and vitamin D).

The IOM suggests the plasma 25(OH)D threshold for vitamin D deficiency is $30 \mathrm{nmol} / \mathrm{l}$ and between 30 and $50 \mathrm{nmol} / \mathrm{l}$ is generally considered inadequate for bone and overall health in the general population ${ }^{(24)}$. According to IOM criteria $90 \%$ ( $n$ 18) of participants in the validation group had 25(OH)D plasma below $50 \mathrm{nmol} / 1$ and $70 \%$ ( $n$ 16) had status $<30 \mathrm{nmol} / \mathrm{l}$. Part of the reason for low vitamin D status is ascribed to the late winter collection of blood samples (March 2011). According to studies from other European countries, the prevalence of hypovitaminosis $\mathrm{D}$ is highest during the winter and early spring (January-March). For example, in a study conducted between February and March in Finland, serum 25(OH)D concentration of healthy women was $47 \mathrm{nmol} / \mathrm{l}$ on average ${ }^{(40)}$. Similarly, when serum $25(\mathrm{OH}) \mathrm{D}$ concentrations were measured in a population of healthy adults from Ireland prevalence rates for serum $25(\mathrm{OH}) \mathrm{D}$ concentrations $<30 \mathrm{nmol} / 1$ and $<50 \mathrm{nmol} / 1$ were $11 \%$ and $55 \%$ in winter, respectively ${ }^{(41)}$. Overall in Serbia expenditure on seafood and fish, as a main natural source of vitamin D, is extremely low $(3.1 \%$ of total expenditure on food) due to dietary habits and traditional cuisine based mostly on meat ${ }^{(42)}$.

According to other studies, for most nutrients, correlation coefficients with biomarkers are in the range of 0.3 to $0.5^{(43)}$ and these correlations provide useful and objective evidence for the validity of nutrient intake assessed by a dietary instrument. In our study, the Spearman rank-correlation coefficient between total vitamin D intake assessed by the FFQ and biomarker showed moderate agreement, with a correlation coefficient for energy-adjusted vitamin D intake ( $r=0.415, P=0.001)$ similar to the crude value $(r=0.422$, $P=0 \cdot 032$ ). One possible reason for the moderate agreement between total vitamin $\mathrm{D}$ intake assessed by the FFQ and biomarker might be the time of the year when samples are collected, at the end of the winter. During winter months, when vitamin D production is minimal, the human body can rely on tissue stores of vitamin D for between 30 and $60 \mathrm{~d}$ assuming levels are adequate prior to winter ${ }^{(44)}$. However, after more than 2 months with inadequate vitamin $\mathrm{D}$ intake, stores are depleted, consistent with the end of winter. In addition, our study participants are young healthy women with percentage of fat and fat mass in the normal range (see online supplementary material, Supplemental Table 1); thus low vitamin D status is not caused by sequestration of vitamin $\mathrm{D}$ in adipose tissue as is observed in those who are obese ${ }^{(45)}$.

In our validation work we chose to assess vitamin D status during a time when UVB sources would be minimal. Our winter-time assessment, combined with the healthy weights of the participants, make this an ideal study framework to look at dietary assessment tools. Results of our study show that no women met the IOM RDA recommendations according to either dietary assessment tool and $96 \%$ did not meet the EAR. Vitamin D intake for $100 \%$ of participants was below the RDA $(15 \mu \mathrm{g} / \mathrm{d})$ and plasma $25(\mathrm{OH}) \mathrm{D}$ concentration was below $50 \mathrm{nmol} / 1$ for $90 \%$ of participants. In the subgroup, all of the vitamin D was from food with no use of dietary supplements. However, the main study group did consume supplements at $4.7 \%$ and intakes from the FFQ and $24 \mathrm{~h}$ recalls were related, suggesting the WRH-FFQ suitably captures this information. As the Serbian market introduces affordable vitamin D-containing supplements as well as single vitamin D supplements for all age ranges, the FFQ should be further adapted to ensure capture of new sources and higher intakes of vitamin D.

It is not mandatory to fortify food with vitamin D in Serbia and therefore milk is not in the top six food sources of vitamin D. Milk consumption assessed by $24 \mathrm{~h}$ recall in our study is 116.5 (SD 90.1) $\mathrm{ml} / \mathrm{d}$ and yoghurt intake is 109.2 (SD 93.6) $\mathrm{ml} / \mathrm{d}$. If just milk was fortified with vitamin $\mathrm{D}$ as is common in North America ${ }^{(46)}(0 \cdot 87-1 \mu \mathrm{g} / 100 \mathrm{ml})$, vitamin D intake would be higher by 1.5 (SD $1 \cdot 1) \mu \mathrm{g} / \mathrm{d}$, which would improve total intake in people but likely not sufficiently enough to improve vitamin D status during the winter months. As vitamin $\mathrm{D}$ is now recognized as one of the 'big two' in vitamin fortification in Europe ${ }^{(47)}$, it might be wise to consider mandatory fortification in Serbia as well.

Strengths of the present validation study include: the nature of data collection (i.e. interviewer-administered FFQ, collection during the winter months); inclusion of overall healthy, non-obese or non-overweight young women; inclusion of detailed food lists with food photographs; questions on intake of supplements; and the vitamin D analyses in a laboratory in Canada.

Even though our study is adequately powered with 422 participants ${ }^{(48,49)}$, only twenty participants were available for the biomarker validation analyses, which is a low sample size. However, other validation studies where the method of triads is applied used a similar number of participants ( $n$ 29). Narrow $95 \%$ confidence intervals for the validity coefficients indicate adequate sample size for the study and it might extend beyond the range of the validity coefficient which was the case in some studies that used a triangular approach ${ }^{(33)}$. A potential limitation of the applied method of triads is the impact of using a single measure of $25(\mathrm{OH}) \mathrm{D}$ which does not account for random measurement error in the biomarker ${ }^{(50)}$. An additional limitation that might have a potential impact on the study results is correlated person-specific bias between selfreport instruments, which may inflate the observed validity of the self-report instruments ${ }^{(51,52)}$. The main reason why some of the participants were classified in the opposite quartile during cross-classification (20\%) was due to fish consumption (tuna steak or fish pate) reported in our $30 \mathrm{~d}$ WRH-FFQ but not in any of the three $24 \mathrm{~h}$ recalls (see online supplementary material, Supplemental Table 2). Agreement between the FFQ and three $24 \mathrm{~h}$ recalls as assessed in the Bland-Altman plots using the log values 
clarifies that the relationship is not different across the group among participants, which accounts for well-known fact that as the intake increases the variation will also increase. Although the $24 \mathrm{~h}$ recall method tends to rely on memory of the participants and the ability to evaluate portion sizes, in our study it is not a weakness since our participants were young healthy women and we used a food photograph album ${ }^{(53)}$. The main strengths of our FFQ are the inclusion of traditional foods used in the CEE region and its ease of administration, enhanced by inclusion of food photographs that emphasized portion sizes, which reduced time needed for administration to less than $30 \mathrm{~min}^{(53)}$. Additional advantages of our FFQ are the potential use as a dietary assessment tool in health and some clinical research due to the low cost of administration and processing.

However, all of our participants were highly educated and thus further studies among women from other segments of the population are required to ensure that the WRH-FFQ is valid.

\section{Conclusion}

To our knowledge, the present study is among the first to assess the validity of intake of vitamin D using the method of triads. The upper limits of the validity coefficients were less than one and validity coefficients were high between the true intake and the FFQ $(0.847)$ and $24 \mathrm{~h}$ recall $(0.810)$, which reflects a strong relationship, although this is not the case for the biomarker (0.499). This suggests that the applied WRH-FFQ is a valid tool for assessing dietary vitamin $\mathrm{D}$ intake in women living in Serbia, a region without mandatory vitamin D food fortification. Furthermore, the study provided novel data regarding vitamin D intake and status of young Serbian women with important ramifications for public health nutrition policy.

\section{Acknowledgements}

Financial support: This work was supported by the Ministry of Education, Science and Technological Development of the Republic of Serbia (grant numbers III 41030, 46013 and 41028). The Ministry of Education, Science and Technological Development of the Republic of Serbia had no role in the design, analysis or writing of this article. Conflict of interest: The authors declare that there are no conflicts of interest. Authorship: M. Glibetic formulated the research questions; M. Gurinovic and L.M.M. designed the research; M.D.-I. and A.K. conducted research; H.A.W. and M.D.-I. conducted biochemical analyses; M.D.-I., H.A.W. and M.N. analysed data; M.D.-I. and H.A.W. drafted and revised the paper; M.D.-I. had primary responsibility for the final content. All authors read and approved the final manuscript. Ethics of buman subject participation: The study was conducted according to the guidelines laid down in the Declaration of Helsinki and all procedures were approved by the Ethics Review Board in Serbia and the McGill Institutional Review Board of the Faculty of Agricultural and Environmental Science for analyses in Canada. Written informed consent was obtained from all participants.

\section{Supplementary material}

To view supplementary material for this article, please visit http://dx.doi.org/10.1017/S136898001500138X

\section{References}

1. Ramakrishnan U, Grant F, Goldenberg T et al. (2012) Effect of women's nutrition before and during early pregnancy on maternal and infant outcomes: a systematic review. Paediatr Perinat Epidemiol 26, Suppl. 1, 285-301.

2. Basit S (2013) Vitamin D in health and disease: a literature review. Br J Biomed Sci 70, 161-172.

3. Kaludjerovic J \& Vieth R (2010) Relationship between vitamin $\mathrm{D}$ during perinatal development and health. J Midwifery Womens Health 55, 550-560.

4. Grober U, Spitz J, Reichrath J et al. (2013) Vitamin D: Update 2013: From rickets prophylaxis to general preventive healthcare. Dermatoendocrinology 5, 331-347.

5. Wei SQ, Qi HP, Luo ZC et al. (2013) Maternal vitamin D status and adverse pregnancy outcomes: a systematic review and meta-analysis. J Matern Fetal Neonatal Med 26, 889-899.

6. Hypponen E, Cavadino A, Williams D et al. (2014) Vitamin D and pre-eclampsia: original data, systematic review and meta-analysis. Ann Nutr Metab 63, 331-340.

7. Ross AC, Manson JE, Abrams SA et al. (2011) The 2011 report on dietary reference intakes for calcium and vitamin D from the Institute of Medicine: what clinicians need to know. J Clin Endocrinol Metab 96, 53-58.

8. Secura G (2013) Long-acting reversible contraception: a practical solution to reduce unintended pregnancy. Minerva Ginecol 65, 271-277.

9. Novakovic R, Cavelaars AE, Bekkering GE et al. (2013) Micronutrient intake and status in Central and Eastern Europe compared with other European countries, results from the EURRECA network. Public Health Nutr 16, 824-840.

10. Mensink GB, Fletcher R, Gurinovic M et al. (2013) Mapping low intake of micronutrients across Europe. Br J Nutr 110, 755-773.

11. Willett WC, Sampson L, Stampfer MJ et al. (1985) Reproducibility and validity of a semiquantitative food frequency questionnaire. Am J Epidemiol 122, 51-65.

12. Block G, Woods M, Potosky A et al. (1990) Validation of a self-administered diet history questionnaire using multiple diet records. J Clin Epidemiol 43, 1327-1335.

13. Willett WC (1998) Nutritional Epidemiology, 2nd ed., pp. 301-315. New York: Oxford University Press.

14. Potischman N (2003) Biologic and methodologic issues for nutritional biomarkers. J Nutr 133, Suppl. 3, 875S-880S.

15. Kaaks RJ (1997) Biochemical markers as additional measurements in studies of the accuracy of dietary questionnaire measurements: conceptual issues. Am J Clin Nutr 65, 4 Suppl., 1232S-1239S.

16. Statistical office of the Republic of Serbia (2011) Population. Age and sex. Data by settlements. http://pod2.stat.gov.rs/ ObjavljenePublikacije/Popis2011/Starost\%20i\%20pol-Age\% 20 and\%20sex.pdf (accessed February 2015). 
17. Block G \& Subar AF (1992) Estimates of nutrient intake from a food frequency questionnaire: the 1987 National Health Interview Survey. I Am Diet Assoc 92, 969-977.

18. Colic Baric I, Satalic Z, Keser I et al. (2009) Validation of the folate food frequency questionnaire with serum and erythrocyte folate and plasma homocysteine. Int J Food Sci Nutr 60, Suppl. 5, 10-18.

19. Subar AF, Dodd KW, Guenther PM et al. (2006) The food propensity questionnaire: concept, development, and validation for use as a covariate in a model to estimate usual food intake. J Am Diet Assoc 106, 1556-1563.

20. Gurinovic M, Milesevic J, Kadvan A et al. (2015) Establishment and advances in the first online Serbian food and recipe data base harmonized with EuroFIR ${ }^{\mathrm{TM}}$ standards. Food Chem, http://dx.doi.org/10.1016/j.foodchem.2015.01.107.

21. Gurinovic M, Milesevic J, Novakovic R et al. (2015) Improving nutrition surveillance and public health research in Central and Eastern Europe/Balkan countries using the Balkan food platform and dietary tools. Food Chem, http:// dx.doi.org/10.1016/j.foodchem.2015.03.103.

22. Willett WC, Howe GR \& Kushi LH (1997) Adjustment for total energy intake in epidemiologic studies. Am J Clin Nutr 65, 4 Suppl., 1220S-1228S.

23. Flood A, Peters U, Chatterjee $\mathrm{N}$ et al. (2005) Calcium from diet and supplements is associated with reduced risk of colorectal cancer in a prospective cohort of women. Cancer Epidemiol Biomarkers Prev 14, 126-132.

24. Ross A, Taylor C, Yaktine A et al. (editors) (2011) Dietary Reference Intakes for Calcium and Vitamin D, pp. 75-78. Washington, DC: National Academies Press.

25. Barr SI (2006) Applications of Dietary Reference Intakes in dietary assessment and planning. Appl Physiol Nutr Metab 31, 66-73.

26. Institute of Medicine (2001) Dietary Reference Intakes. Washington, DC: National Academy Press.

27. Zerwekh JE (2008) Blood biomarkers of vitamin D status. Am J Clin Nutr 87, issue 4, 1087S-1091S.

28. Bland JM \& Altman DG (1999) Measuring agreement in method comparison studies. Stat Methods Med Res 8 , 135-160.

29. Ocke MC \& Kaaks RJ (1997) Biochemical markers as additional measurements in dietary validity studies: application of the method of triads with examples from the European Prospective Investigation into Cancer and Nutrition. Am J Clin Nutr 65, 4 Suppl., 1240S-1245S.

30. Kabagambe EK, Baylin A, Allan DA et al. (2001) Application of the method of triads to evaluate the performance of food frequency questionnaires and biomarkers as indicators of long-term dietary intake. Am J Epidemiol 154, 1126-1135.

31. Ross AC (2011) The 2011 report on dietary reference intakes for calcium and vitamin D. Public Health Nutr 14, 938-939.

32. Ross AC, Manson JE, Abrams SA et al. (2011) The 2011 dietary reference intakes for calcium and vitamin $\mathrm{D}$ : what dietetics practitioners need to know. J Am Diet Assoc 111, 524-527.

33. McNaughton SA, Marks GC, Gaffney P et al. (2005) Validation of a food-frequency questionnaire assessment of carotenoid and vitamin E intake using weighed food records and plasma biomarkers: the method of triads model. Eur J Clin Nutr 59, 211-218.

34. Shuaibi AM, Sevenhuysen GP \& House JD (2008) Validation of a food choice map with a 3-day food record and serum values to assess folate and vitamin B-12 intake in collegeaged women. J Am Diet Assoc 108, 2041-2050.
35. Verkleij-Hagoort AC, de Vries JH, Stegers MP et al. (2007) Validation of the assessment of folate and vitamin $\mathrm{B}_{12}$ intake in women of reproductive age: the method of triads. Eur $J$ Clin Nutr 61, 610-615.

36. Daures JP, Gerber M, Scali J et al. (2000) Validation of a food-frequency questionnaire using multiple-day records and biochemical markers: application of the triads method. J Epidemiol Biostat 5, 109-115.

37. Gurinovic M, Kadvan A \& Vukotic M (2011) The quality of nutrition in schoolchildren and adult members of families. In Yugoslav Study of Atherosclerosis Precursors in Schoolchildren in Serbia: Twenty Years Follow-up, pp. 343-368 [S Nedeljkovic, editor]. Belgrade: Medical Faculty.

38. Elmadfa I \& Freisling H (2009) Nutritional status in Europe: methods and results. Nutr Rev 67, Suppl. 1, S130-S134.

39. Rodler I, Biro L, Greiner E et al. (2005) Dietary survey in Hungary, 2003-2004. Orv Hetil 146, 1781-1789.

40. Lamberg-Allardt CJ, Outila TA, Karkkainen MU et al. (2001) Vitamin D deficiency and bone health in healthy adults in Finland: could this be a concern in other parts of Europe? J Bone Miner Res 16, 2066-2073.

41. Cashman KD, Muldowney S, McNulty B et al. (2013) Vitamin D status of Irish adults: findings from the National Adult Nutrition Survey. Br J Nutr 109, 1248-1256.

42. Euromonitor International (2010) Consumer lifestyle in Serbia. http://www.euromonitor.com/consumer-lifestyles-inserbia/report (accessed August 2014).

43. Hu F (editor) (2008) Obesity Epidemiology, pp. 97-99. New York: Oxford University Press.

44. Mawer EB, Backhouse J, Holman CA et al. (1972) The distribution and storage of vitamin D and its metabolites in human tissues. Clin Sci 43, 413-431.

45. Vimaleswaran KS, Berry DJ, Lu C et al. (2013) Causal relationship between obesity and vitamin $\mathrm{D}$ status: bi-directional Mendelian randomization analysis of multiple cohorts. PLoS Med 10, e1001383.

46. Calvo MS, Whiting SJ \& Barton CN (2004) Vitamin D fortification in the United States and Canada: current status and data needs. Am J Clin Nutr 80, 6 Suppl., 1710S-1716S.

47. de Lourdes Samaniego-Vaesken M, Alonso-Aperte E \& Varela-Moreiras G (2012) Vitamin food fortification today. Food Nutr Res 2012, 56.

48. Osowski JM, Beare T \& Specker B (2007) Validation of a food frequency questionnaire for assessment of calcium and bone-related nutrient intake in rural populations. J Am Diet Assoc 107, 1349-1355.

49. Pritchard JM, Seechurn T \& Atkinson SA (2010) A food frequency questionnaire for the assessment of calcium, vitamin D and vitamin K: a pilot validation study. Nutrients 2, 805-819.

50. Preis SR, Spiegelman D, Zhao BB et al. (2011) Application of a repeat-measure biomarker measurement error model to 2 validation studies: examination of the effect of within-person variation in biomarker measurements. Am J Epidemiol 173, 683-694.

51. Kipnis V, Midthune D, Freedman L et al. (2002) Bias in dietary-report instruments and its implications for nutritional epidemiology. Public Health Nutr 5, 915-923.

52. Kipnis V, Midthune D, Freedman LS et al. (2001) Empirical evidence of correlated biases in dietary assessment instruments and its implications. Am J Epidemiol 153, 394-403.

53. Cade J, Thompson R, Burley V et al. (2002) Development, validation and utilisation of food-frequency questionnaires a review. Public Health Nutr 5, 567-587. 